\title{
ANALISIS SENSORI DAN AKTIVITAS ANTIOKSIDAN MENGGUNAKAN METODE DPPH PADA CAMPURAN BAWANG PUTIH, JAHE, LEMON DAN MADU SEBAGAI SUPLEMEN HERBAL
}

\author{
[Sensory Analysis and Antioxidant Activity Using DPPH Method in Garlic, Ginger, Lemon and Honey \\ Mixes as an Herbal Supplement]
}

\author{
Suci Rahmi ${ }^{*}$, Hasanuddin Husin \\ Jurusan Teknologi Hasil Pertanian, Fakultas Pertanian, \\ Universitas Teuku Umar, Alue Peunyareng, Meurebo, Aceh Barat 23681 \\ Email*): Sucirahmi@utu.ac.id
}

Diterima 12 Desember 2019 / Disetujui 7 Juli 2020

\begin{abstract}
Herbal supplements are one of the products that are taken from outside the body derived from a mixture of herbal plant ingredients have antioxidant activity to prevent the presence of free radicals in the body. Testing natural antioxidant activity in herbal supplement products using the DPPH method $(1,1$ dipheny/-2-picry/hyrazil). Measurement of UV-Visible spectrophotometry absorbance with DPPH absorbance value at a wavelength of $517 \mathrm{~nm}$. Sensory analysis using a hedonic test at the panelist preference level, using four attribute parameters namely taste, aroma, color and overall acceptance. Results Tests of antioxidant activity in herbal supplement products on various combination techniques and concentrations of garlic, ginger, local lemons and honey, resulting in the reduction of DPPH which is characterized by a reduction in the intensity of the color from purple to fade to yellow. Antioxidant testing obtained IC50 values from all herbal supplement samples from various treatment techniques and concentrations showed IC50 values less than 50 found in the treatment of chopped engineering materials, concentration 1 (K1) of $23.97 \%$. While concentrations of $2(\mathrm{k} 2)$ and $3(\mathrm{k} 3)$ as well as in various combination techniques and other concentrations indicate that IC50 values range from $50 \mathrm{ppm}$ to $100 \mathrm{ppm}$. This shows that herbal supplements have very strong antioxidants (IC50 value <50) found in the treatment of ingredients with chopped techniques with the lowest concentration. whereas herbal supplements with treatment techniques and other concentrations have a strong antioxidant value of IC50 (50-100). The results of sensory analysis indicate that the average panelist had a preference level for herbal supplement products with chopping and extraction treatment techniques.
\end{abstract}

Keywords: Antioxidant, DPPH, Herbal supplements, $I C_{50}$

\section{ABSTRAK}

Suplemen herbal merupakan salah satu produk yang menjadi asupan dari luar tubuh yang berasal dari hasil campuran bahan tanaman herbal yang mempunyai aktivitas antioksidan tinggi untuk mencegah adanya radikal bebas dalam tubuh. Pengujian aktivitas antioksidan alami pada produk suplemen herbal menggunakan metode DPPH (1,1-diphenyl-2-picrylhyrazil). Pengukuran absorbansi secara spektrofotometriUV Visibel dengan Nilai absorbansi DPPH pada panjang gelombang $517 \mathrm{~nm}$. Analisis sensori dengan menggunakan uji hedonik pada tingkat kesukaan panelis, menggunakan empat parameter atribut yaitu rasa, aroma, warna dan penerimaan keseluruhan. Hasil Pengujian aktivitas antioksidan dalam produk suplemen herbal pada berbagai teknik kombinasi dan konsentrasi bawang putih, jahe, lemon lokal dan madu, menghasilkan peredaman DPPH yang ditandai dengan berkurangnya intensitas warna ungu menjadi pudar sampai kekuningan. Pengujian Antioksidan didapatkan Nilai $\mathrm{IC}_{50}$ dari seluruh sampel suplemen herbal dari berbagai teknik perlakuan dan konsentrasi menunjukkan nilai $\mathrm{IC}_{50}$ kurang dari 50 terdapat pada perlakuan bahan teknik rajangan, konsentrasi $1\left(K_{1}\right)$ sebesar $23,97 \%$. Sementara konsentrasi $2\left(k_{2}\right)$ dan $3\left(k_{3}\right)$ serta pada berbagai teknik kombinasi dan konsentrasi lainnya menunjukan bahwa nilai $\mathrm{IC}_{50}$ berkisar $50 \mathrm{ppm}-100$ ppm. Hal ini menunjukkan bahwa suplemen herbal memiliki antioksidan yang sangat kuat (nilai $\mathrm{IC}_{50}<50$ ) terdapat pada perlakuan bahan dengan teknik rajangan dengan konsentrasi yang paling rendah, sedangkan suplemen herbal dengan teknik perlakuan dan konsentrasi lain memiliki nilai antioksidan kuat IC 50 (50-100) ppm. Hasil analisis sensori menunjukan bahwa rata-rata panelis memiliki tingkat kesukaan pada produk suplemen herbal dengan teknik perlakuan rajangan dan perlakuan sari.

Kata kunci: Antioksidan, DPPH, IC $_{50}$, Sensori, Suplemen Herbal.

PENDAHULUAN

Indonesia merupakan salah satu negara sentral produksi tanaman herbal.
Sebagian besar masyarakat memanfaatkan tanaman herbal untuk pengobatan berbagai macam penyakit. Pengobatan tradisional yang berasal dari tanaman herbal sudah 
lama dikenal seperti jahe merah, bawang putih, apel, lemon dan madu (Mantiri $d k k$., 2013). Tanaman ini dapat digunakan sebagai bahan pangan dan juga digunakan dalam pengobatan.

Kandungan senyawa vitamin C, asam sitrat, minyak atsiri, bioflavonoid, polifenol, kumarin, flavonoid, dan minyak-minyak volatil yang terkandung di dalam bahan tanaman dapat menangkal stres oksidatif di tubuh manusia dengan cara membantu mempertahankan keseimbangan antara oksidan dan antioksidan. Stres oksidatif adalah suatu keadaan ketika kandungan oksidan dan radikal bebas di dalam tubuh lebih banyak dibandingkan antioksidan (Mateen et al., 2016).

Antioksidan adalah senyawa yang mampu menunda, memperlambat dan mencegah proses oksidasi lipid. Dalam arti khusus antioksidan adalah zat yang dapat menunda atau mencegah terjadinya reaksi radikal bebas dalam oksidasi lipid (Ahmad dkk., 2012). Sumber antioksidan dapat diperoleh secara alami dan sintetik. Antioksidan alami merupakan senyawa antioksidan yang terdapat secara alami dalam tubuh sebagai mekanisme pertahanan tubuh normal maupun berasal dari asupan luar tubuh. Antioksidan sintetik merupakan senyawa yang disintesis secara kimia. Antioksidan alami dari dalam tubuh yang dihasilkan tidak cukup untuk melawan radikal bebas di dalam tubuh yang berlebih, untuk itu diperlukan masukan antioksidan dari luar tubuh (Winarsi, 2007).

Suplemen herbal merupakan salah satu produk yang menjadi asupan antioksidan alami yang berasal dari hasil campuran bahan tanaman herbal. Bawang putih (Allium sativum) mengandung antioksidan yang dapat mendukung mekanisme pelindung tubuh dan dapat dimanfaatkan sebagai terapeutik (Prasonto dkk., 2017). Jahe (Zingiber officinale) mengandung senyawa volatile dan non volatile yang terdiri dari berbagai senyawa flavonoid dan polifenol yang mempunyai aktivitas antioksidan tinggi untuk mencegah adanya radikal bebas dalam tubuh (Supriyanti, 2015). Begitu pula buah lemon (Citrus limon L) juga memiliki kandungan bioflavonoid, polifenol, kumarin yang memiliki manfaat sebagai antioksidan alami (Nizhar, 2012).

Asupan antioksidan dari Suplemen Herbal membutuhkan tingkat kesukaan organoleptik. Analisis sensori merupakan suatu metode yang dilakukan oleh manusia menggunakan panca indera manusia untuk menilai atribut organoleptik pada produk, seperti warna, bentuk, rasa, aroma dan tekstur. Menurut (Batch dkk., 2012; Kraujalyte $\left.d k k_{.}, 2012\right)$, bidang penilaian sensori memerlukan subjek untuk menilai produk. Subjek ini kemudian disebut sebagai panelis, dan panelis dapat dibedakan menjadi panelis konsumen, panelis jenis konsumen, dan panelis laboratorium.

Oleh sebab itu penelitian ini bertujuan untuk untuk menganalisis sensori dan kandungan antioksidan dari campuran bawang putih, jahe, lemon dan madu pada suplemen herbal dengan menggunakan pengukuran absorbansi DPPH secara spektrofotometri visible.

\section{BAHAN DAN METODE}

\section{Alat dan Bahan}

Bahan suplemen herbal yang digunakan pada penelitian ini adalah bawang putih, jahe, lemon lokal, madu, diperoleh dari pasar induk Lambaro kabupaten Aceh Besar. Bahan analisis sensori adalah air mineral, bubuk kopi, dan kuisioner. Pengujian antioksidan yang digunakan adalah DPPH, etanol $70 \%$, aquades, alumunium foil, kertas label.

Alat yang digunakan pada pengujian antioksidan adalah spektrofotometri Uv-vis tipe evolution 201 (Thermo, Inggris), kuvet, timbangan analitik (Kern ABJ, Jerman), beaker glass, pengaduk kaca, labu takar 50 $\mathrm{ml}$ dan $100 \mathrm{ml}$, pipet ukur $2 \mathrm{ml}$ dan $5 \mathrm{ml}$, tabung reaksi, vortex, kamera.

\section{Metode}

Pengujian aktivitas antioksidan pada produk suplemen herbal dilakukan melalui 
Versi Online:

http://www.profood.unram.ac.id/index.php/profood e-ISSN: 2443-3446

beberapa tahapan penelitian yang meliputi : pengambilan bahan dan pengolahan, penyaringan (filtrasi) produk, uji aktivitas antioksidan sampel suplemen herbal dan penentuan nilai $\mathrm{IC}_{50}$.

\section{Pengambilan bahan dan Pengolahan}

Bahan pembuatan suplemen herbal yang digunakan pada penelitian ini adalah masing-masing pada konsentrasi $1 \quad\left(\mathrm{~K}_{1}\right)$ bawang putih $150 \mathrm{~g}$ dan jahe $150 \mathrm{~g}$, lemon $300 \mathrm{~g}$. konsentrasi $2\left(\mathrm{k}_{2}\right)$ bawang putih $200 \mathrm{~g}$ dan jahe $200 \mathrm{~g}$, lemon $400 \mathrm{~g}$. Konsentrasi 3 $\left(\mathrm{K}_{3}\right)$ bawang putih $250 \mathrm{~g}$ dan jahe $250 \mathrm{~g}$, lemon $500 \mathrm{~g}$. Penambahan madu pada masing-masing perlakuan dan konsentrasi sebesar $1000 \mathrm{~g}$ yang diperoleh dari pasar induk Lambaro kabupaten Aceh Besar. Pada tahap pengolahan produk suplemen herbal menggunakan 4 teknik perlakuan yaitu perajangan, puree, perlakuan sari, perlakuan sari dengan pemanasan. Bawang putih, jahe, lemon lokal dilakukan sortasi dan pencucian. Setelah itu dilakukan pengubahan bentuk berdasarkan 4 teknik perlakuan penelitian. Campuran bawang putih, jahe, lemon lokal dan madu tersebut di simpan dalam toples tertutup selama 7 hari penyimpanan. Campuran bahan suplemen dilakukan pengadukan setiap hari, agar bahan didalam toples dapat homogen.

\section{Penyaringan (Filtrasi) produk}

Campuran bawang putih, jahe, lemon lokal dan madu dilakukan filtrasi (penyaringan) setelah 7 hari penyimpanan. Penyaringan ini bertujuan untuk memisahkan ampas bahan selama pengolahan. Hasil dari filtrasi simpan dalam wadah tertutup.

\section{Pengujian Antioksidan}

\section{Pembuatan Larutan DPPH (Dewi et al.} 2016)

Larutan DPPH dibuat dengan cara menimbang DPPH sebanyak 0,0098 gram, ditambahkan etanol $70 \%$ kedalam labu ukur sebanyak $50 \mathrm{ml}$, kemudian diaduk hingga larut. Selanjutnya diambil larutan tersebut sebanyak $20 \mathrm{ml}$ dan dilarutkan dengan 100 $\mathrm{ml}$ etanol absolut dalam labu ukur $100 \mathrm{ml}$.
Pro Food (Jurnal Ilmu dan Teknologi Pangan)

Vol 6 No. 1 Mei 2020

ISSN: 2443-1095

\section{Pembuatan Larutan Sampel}

Larutan sampel dibuat dengan cara mengambil sampel suplemen herbal menggunakan pipet ukur sebanyak 0,2 ml, kemudian dimasukkan kedalam tabung reaksi. selanjutnya di tambahkan larutan DPPH sebanyak 3,8 ml, dan di vortex selama 1 menit. Larutan sampel dilakukan inkubasi dalam ruangan gelap selama 30 menit.

\section{Pembuatan Larutan blanko}

Blanko dilakukan dengan memipet 3,8 $\mathrm{ml}$ DPPH. Divortex dan diinkubasi pada ruangan gelap. Diukur absorbansinya pada panjang gelombang $517 \mathrm{~nm}$.

\section{Pengujian Sampel}

Sampel dari 4 teknik perlakuan penelitian yang telah di inkubasi selama 30 menit di uji nilai absorbansinya menggunakan spektrofotometer Uv-vis pada panjang gelombang $517 \mathrm{~nm}$. kapasitas antioksidan masing-masing sampel dihitung sebagai persentase inhibisi radikal DPPH.

\section{Penentuan nilai $\mathbf{I C}_{50}$}

Menurut Dewi et al. (2016), analisis pengujian antioksidan metode DPPH dilakukan dengan melihat perubahan warna masing-masing sampel setelah di inkubasi bersama DPPH. Jika semua elektron DPPH berpasangan dengan elektron pada sampel larutan maka akan terjadi perubahan warna sampel dimulai dari ungu tua hingga kuning terang.

Kemudian sampel diukur nilai absorbansi menggunakan spektrofotometr iUv-Vis pada panjang gelombang $517 \mathrm{~nm}$ dengan Formula :

$$
\text { Antioksidan } \left.=\frac{\mathrm{A}_{0}-\mathrm{A}_{1}}{\mathrm{~A}_{0}} \times 100 \ldots 1\right)
$$

Dimana :

$$
\begin{aligned}
& A_{0}=\text { Nilai Absorbansi kontrol (Blanko) } \\
& A_{1}=\text { Nilai Absorbansi Sampel }
\end{aligned}
$$

\section{Analisis Sensori}

Analisis sensori dilakukan dari hasil pengolahan bawang putih, jahe, lemon lokal dan madu sebagai suplemen herbal dengan empat kriteria mutu yaitu rasa, aroma, 
Versi Online:

http://www.profood.unram.ac.id/index.php/profood e-ISSN: 2443-3446

warna, dan atribut keseluruhan (overall). Uji yang digunakan adalah uji rating hedonik (SNI 01-2346-2006). Panelis yang digunakan adalah panelis tidak terlatih dengan jumlah 15 orang. Pada penelitian ini digunakan 7 skala hedonik dengan urutan skala 1 menyatakan sangat tidak suka, skala 2 menyatakan tidak suka, skala 3 menyatakan agak tidak suka, skala 4 menyatakan agak suka, skala 5 menyatakan suka, skala 6 menyatakan sangat suka, skala 7 menyatakan amat sangat suka.

\section{HASIL DAN PEMBAHASAN}

\section{Antioksidan}

Teknik kombinasi dan konsentrasi pada campuran bawang putih, jahe, lemon lokal dan madu dilakukan dengan cara 4 perlakuan dan 3 taraf konsentrasi yaitu teknik perajangan, penghalusan (puree), pengambilan sari, dan perlakuan sari bahan dengan proses pemanasan. Taraf konsentrasi bahan pembuatan suplemen herbal masingmasing pada konsentrasi 1 ( $\left.\mathrm{K}_{1}\right)$ bawang putih $150 \mathrm{~g}$ dan jahe $150 \mathrm{~g}$, lemon $300 \mathrm{~g}$. konsentrasi $2\left(\mathrm{k}_{2}\right)$ bawang putih $200 \mathrm{~g}$ dan jahe $200 \mathrm{~g}$, lemon $400 \mathrm{~g}$. Konsentrasi $3\left(\mathrm{~K}_{3}\right)$ bawang putih $250 \mathrm{~g}$ dan jahe $250 \mathrm{~g}$, lemon 500 g. Penambahan madu pada masingmasing perlakuan dan konsentrasi sebesar $1000 \mathrm{~g}$. Hasil campuran pengolahan bahan difiltrasi menjadi sampel suplemen herbal.

Pengujian aktivitas antioksidan dalam produk suplemen herbal dilakukan untuk mengetahui jumlah persentase aktivitas
Pro Food (Jurnal Ilmu dan Teknologi Pangan)

Vol 6 No. 1 Mei 2020

ISSN: 2443-1095

pengikatan terhadap radikal bebas. Hasil pengujian kualitatif menunjukkan aktivitas antioksidan, hasil peredaman radikal bebas DPPH yang ditandai dengan perubahan warna dari ungu menjadi pudar sampai kekuningan.

Menurut Jothy $d k k .,(2011)$, Warna DPPH awal adalah ungu, ketika diberikan larutan uji sampel dan warna ungu memudar, maka reaksi peredaman radikal bebas (DPPH) telah terjadi. Semakin muda warna ungu yang dihasilkan, semakin besar daya peredamannya, sehingga antioksidan yang dihasilkan oleh larutan uji semakin tinggi. Parameter ukuran yang dipakai untuk menunjukkan aktivitas antioksidan metode DPPH (1,1-difenil-2-pikrilhidrazil) adalah nilai konsentrasi inhibisi (Inhibition Concentration) IC 50 yaitu konsentrasi suatu zat antioksidan yang dapat menyebabkan 50\% DPPH (1,1difenil-2-pikrilhidrazil) kehilangan karakter radikal atau konsentrasi suatu zat antioksidan yang memberikan persentase (\%) penghambatan 50\%. Gambar 1. Hasil pengujian daya antioksidan suplemen herbal dengan metode DPPH kualitatif (reaksi warna).

Hasil pengujian nilai absorbansi
suplemen herbal menggunakan
spektrofotometri Uv-Vis pada panjang gelombang $517 \mathrm{~nm}$ menunjukkan persentase berbeda-beda pada setiap teknik perlakuan dan 3 taraf konsentrasi campuran bahan. Hasil uji antioksidan suplemen herbal menggunakan metode DPPH dapat dilihat pada Tabel 1.

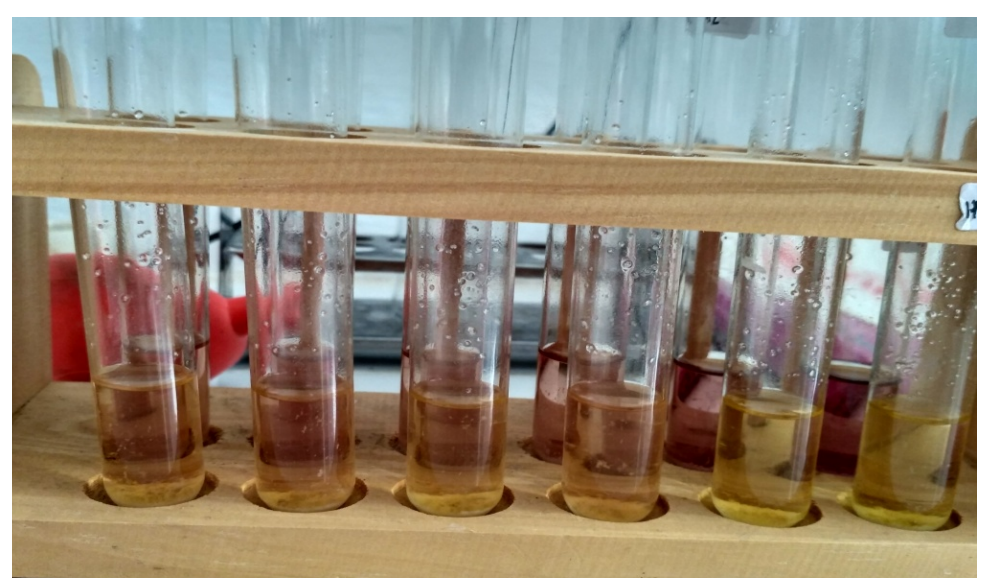

Gambar 1. Reaksi perubahan warna hasil uji daya antioksidan 
Tabel 1. Data nilai \% Antioksidan sampel suplemen herbal.

\begin{tabular}{|c|c|c|c|c|c|c|c|}
\hline \multirow[b]{2}{*}{ Perlakuan } & \multirow[b]{2}{*}{ Konsentrasi } & \multirow{2}{*}{$\begin{array}{c}\text { Absorbansi } \\
\text { Kontrol }\end{array}$} & \multicolumn{3}{|c|}{ Absorbansi } & \multirow{2}{*}{$\begin{array}{l}\text { Rata- } \\
\text { rata }\end{array}$} & \multirow{2}{*}{$\begin{array}{c}\% \\
\text { Antioksidan }\end{array}$} \\
\hline & & & $\begin{array}{c}\text { Data } \\
1\end{array}$ & $\begin{array}{c}\text { Data } \\
2\end{array}$ & $\begin{array}{c}\text { Data } \\
\mathbf{3}\end{array}$ & & \\
\hline \multirow{4}{*}{$\begin{array}{l}\text { Rajangan } \\
\text { (R) }\end{array}$} & K1 & 0,584 & 0,484 & 0,404 & 0,444 & 0,444 & 23,97 \\
\hline & K2 & 0,584 & 0,299 & 0,273 & 0,286 & 0,286 & 51,02 \\
\hline & K3 & 0,584 & 0,319 & 0,142 & 0,2305 & 0,2305 & 60,53 \\
\hline & K1 & 0,584 & 0,155 & 0,146 & 0,1505 & 0,1505 & 74,22 \\
\hline \multirow[t]{3}{*}{ Puree (P) } & K2 & 0,584 & 0,165 & 0,155 & 0,16 & 0,16 & 72,60 \\
\hline & K3 & 0,584 & 0,24 & 0,12 & 0,18 & 0,18 & 69,17 \\
\hline & K1 & 0,584 & 0,157 & 0,316 & 0,2365 & 0,2365 & 59,50 \\
\hline \multirow[t]{2}{*}{ Sari (S) } & K2 & 0,584 & 0,251 & 0,212 & 0,2315 & 0,2315 & 60,35 \\
\hline & K3 & 0,584 & 0,22 & 0,227 & 0,2235 & 0,2235 & 61,72 \\
\hline \multirow{3}{*}{$\begin{array}{l}\text { Sari Termal } \\
\text { (ST) }\end{array}$} & K1 & 0,584 & 0,183 & 0,194 & 0,1885 & 0,1885 & 67,72 \\
\hline & K2 & 0,584 & 0,146 & 0,213 & 0,1795 & 0,1795 & 69,26 \\
\hline & K3 & 0,584 & 0,234 & 0,168 & 0,201 & 0,201 & 65,58 \\
\hline
\end{tabular}

Berdasarkan Tabel 1, nilai IC 50 dari seluruh sampel suplemen herbal dari berbagai teknik perlakuan dan konsentrasi menunjukkan nilai $\mathrm{IC}_{50}$ kurang dari 50 terdapat pada perlakuan bahan teknik rajangan, konsentrasi $1\left(K_{1}\right)$ sebesar 23,97 $\%$. sementara pada teknik perlakuan pada berbagai konsentrasi lainnya menunjukkan bahwa nilai $\mathrm{IC}_{50}$ berkisar $50-100 \mathrm{ppm}$.

Hal ini menunjukkan bahwa suplemen herbal memiliki antioksidan yang sangat kuat (nilai $\mathrm{IC}_{50}<50$ ) terdapat pada perlakuan bahan dengan teknik rajangan dengan konsentrasi yang paling rendah yaitu konsentrasi $1\left(K_{1}\right)$ bawang putih $150 \mathrm{~g}$ dan jahe $150 \mathrm{~g}$, lemon $300 \mathrm{~g}$. Sedangkan suplemen herbal dengan teknik perlakuan dan konsentrasi lain memiliki nilai antioksidan kuat IC $\mathrm{C}_{50}(50-100) \mathrm{ppm}$. Menurut Molyneux (2004), sifat antioksidan berdasarkan nilai IC 50 dapat dilihat Tabel 2 .

Tabel 2. Sifat Antioksidan berdasarkan nilai $\mathrm{IC}_{50}$

\begin{tabular}{lr}
\hline \multicolumn{1}{c}{ Nilai $\mathbf{I C}_{\mathbf{5 0}}$} & Sifat Antioksidan \\
\hline $50 \mathrm{ppm}<$ & Sangat Kuat \\
$50 \mathrm{ppm}-100 \mathrm{ppm}$ & Kuat \\
$100 \mathrm{ppm}-150 \mathrm{ppm}$ & Sedang \\
$150 \mathrm{ppm}-200 \mathrm{ppm}$ & Lemah \\
\hline
\end{tabular}

Sumber : Molyneux (2004)
Perbedaan nilai IC $_{50}$ pada setiap perlakuan dan konsentrasi menunjukkan variasi jumlah antioksidan yang terkandung didalam sampel suplemen herbal. Hal ini akibat terjadinya kerusakan antioksidan didalam bahan selama pengolahan karena tidak cukup untuk menarik senyawa kimia yang bersifat antioksidan dalam suplemen herbal sehingga kemampuan senyawa antioksidan untuk mengurangi radikal DPPH melalui mekanisme donasi atom hidrogen menjadi rendah.

Selain itu juga dipengaruhi oleh kandungan vitamin $\mathrm{C}$ pada setiap sampel suplemen herbal. Pada teknik perlakuan dan setiap konsentrasi bahan campuran bawang putih, jahe dan lemon menggunakan perbandingan rasio $1: 1: 2$. Rasio 1 bawang putih dan 1 jahe sedangkan Rasio 2 buah lemon lokal. Hal ini menunjukkan bahwa banyaknya campuran buah lemon menghasilkan persentase kandungan vitamin C pada sampel suplemen lebih tinggi. Menurut Suhaling (2010), vitamin C memiliki gugus pendonor elektron. Gugus ini terletak pada atom C2 dan C3. Adanya gugus ini menyebabkan vitamin $\mathrm{C}$ dapat menangkap radikal bebas. Radikal bebas adalah suatu senyawa atau molekul yang mengandung satu atau lebih elektron yang tidak berpasangan pada orbital. adanya elektron tidak berpasangan menyebabkan senyawa 
Versi Online:

http://www.profood.unram.ac.id/index.php/profood e-ISSN: 2443-3446

tersebut sangat reaktif mencari pasangan, dengan cara menyerang dan mengikat elektron yang berada disekitar sehingga memicu timbulnya penyakit (Sunarni et al., 2007).

Antioksidan merupakan senyawa yang berguna mengatasi kerusakan oksidatif akibat radikal bebas dalam tubuh sehingga berperan mencegah berbagai macam penyakit (Muchtadi, 2013). Gambar 2 menunjukkan nilai antioksidan pada suplemen herbal dari berbagai teknik kombinasi dan konsentrasi bawang putih, jahe, lemon dan madu.

Gambar 2. menunjukkan bahwa semakin rendah persentase antioksidan maka nilai IC $_{50}$ semakin kuat daya antioksidannya (Molyneux, 2004). Pada teknik kombinasi bahan baku rajangan dengan konsentrasi rendah (konsentrasi $1\left(\mathrm{~K}_{1}\right)$ bawang putih 150 $\mathrm{g}$ dan jahe $150 \mathrm{~g}$, lemon $300 \mathrm{~g}$ ) dapat menangkal radikal bebas lebih tinggi dibandingkan dengan konsentrasi sedang yaitu $2\left(\mathrm{k}_{2}\right)$ bawang putih $200 \mathrm{~g}$ dan jahe $200 \mathrm{~g}$, lemon $400 \mathrm{~g}$ dan konsentrasi tinggi yaitu konsentrasi $3\left(\mathrm{~K}_{3}\right)$ bawang putih $250 \mathrm{~g}$ dan jahe $250 \mathrm{~g}$, lemon $500 \mathrm{~g}$ pada bahan rajangan. begitu juga pada teknik kombinasi bahan puree, sari, dan sari termal dengan berbagai konsentrasi menghasilkan nilai antioksidan lebih kecil nilai daya antioksidan dalam kategori kuat IC $\mathrm{C}_{50}(50 \mathrm{ppm}-100$ ppm).

Berdasarkan hasil penelitian, senyawa yang memiliki daya antioksidan pada suplemen herbal yaitu flavonoid yang
Pro Food (Jurnal Ilmu dan Teknologi Pangan)

Vol 6 No. 1 Mei 2020

ISSN: 2443-1095

merupakan senyawa polifenol. Kandungan organosulfur dan polifenol merupakan faktor yang penting dan berperan terhadap daya aktivitas antioksidan. Menurut Yuhernita dan Juniarti (2011), senyawa polifenol mempunyai kemampuan untuk menyumbangkan atom hidrogen kepada senyawa radikal bebas, maka aktivitas antioksidan senyawa polifenol dapat dihasilkan pada reaksi netralisasi radikal bebas atau pada penghentian reaksi berantai yang terjadi.

Hal sama yang disampaikan oleh Chao (2014) bahwa aktivitas antioksidan pada senyawa flavonoid, fenolik dan tanin dikarenakan ketiga senyawa tersebut adalah senyawa-senyawa fenol, yaitu senyawa dengan gugus $-\mathrm{OH}$ yang terikat pada karbon cincin aromatik. Senyawa fenol ini mempunyai kemampuan untuk menyumbangkan atom hidrogen sehingga radikal DPPH dapat tereduksi menjadi bentuk yang lebih stabil. Aktivitas peredaman radikal bebas senyawa fenol dipengaruhi oleh jumlah dan posisi hidrogen fenolik dalam molekulnya. Semakin banyak jumlah gugus hidroksil yang dimiliki oleh senyawa fenol maka semakin besar aktivitas antioksidan yang dihasilkan. Oleh sebab itu, suplemen herbal dari campuran tanaman herbal yaitu bawang putih (Allium sativum), jahe (Zingiber officinale), lemon (Citrus limon L) dan madu (Apis) mampu menjadi salah satu alternatif asupan antioksidan alami bagi tubuh.

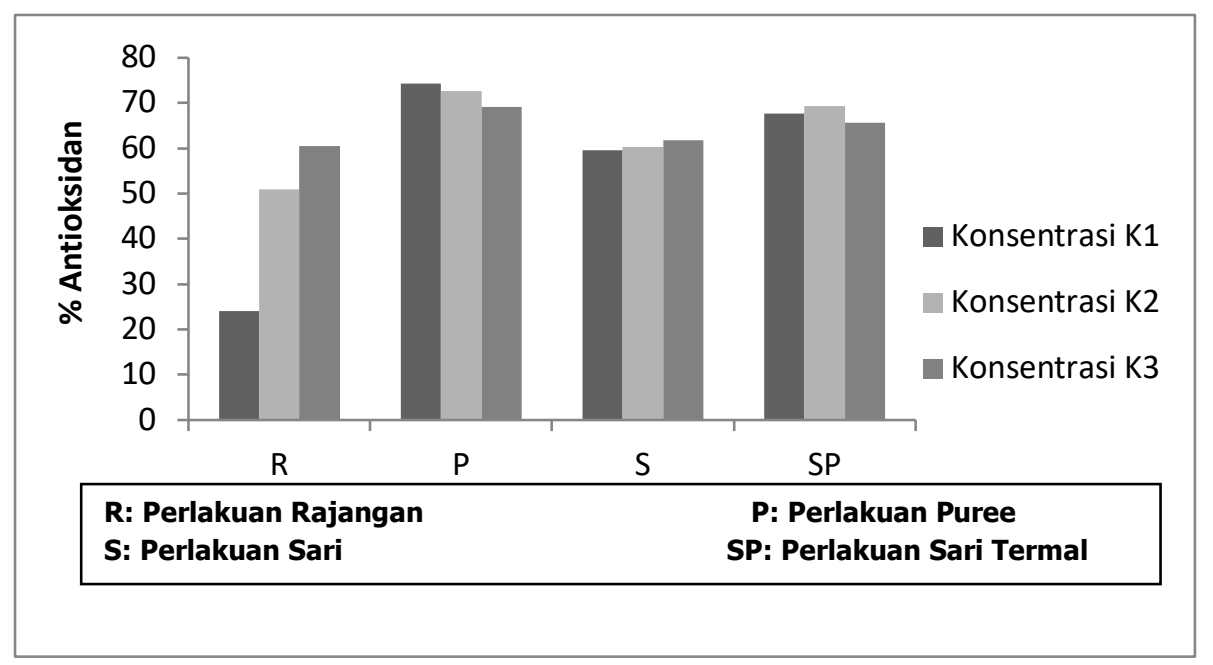

Gambar 2. Grafik nilai Antioksidan suplemen herbal 
Tabel 3. Hasil analisis sensori suplemen herbal

\begin{tabular}{ccccc}
\hline \multirow{2}{*}{ KODE } & \multicolumn{3}{c}{ Rata-rata } \\
\cline { 2 - 5 } & Rasa & Aroma & Warna & Penerimaan Keseluruhan \\
\hline RK1 & 5,7 & 4,8 & 5,2 & 5,1 \\
RK2 & 5,1 & 4,6 & 5,4 & 4,7 \\
RK3 & 4,6 & 3,5 & 5,2 & 4,1 \\
PK1 & 4,7 & 3,2 & 4,1 & 4,0 \\
PK2 & 4,1 & 2,9 & 4 & 3,6 \\
PK3 & 3,9 & 2,5 & 3,9 & 3,4 \\
SK1 & 6 & 2,6 & 5,6 & 4,7 \\
SK2 & 5,6 & 2,5 & 5,5 & 4,5 \\
SK3 & 5,1 & 2,3 & 5,1 & 4,1 \\
SPK1 & 4 & 2,4 & 5,1 & 3,8 \\
SPK2 & 3,7 & 2,5 & 5 & 3,7 \\
SPK3 & 4,6 & 2,6 & 5 & 4,0 \\
\hline
\end{tabular}

\section{Analisis Sensori}

Uji hedonik atau uji kesukaan sangat penting pada suatu produk baru, sehingga harus diketahui daya terima konsumen terhadap produk akhir yang dihasilkan. Hasil penilaian dari uji organoleptik ditampilkan pada Tabel 3.

\section{Rasa}

Rasa merupakan salah satu atribut penting yang mempengaruhi penerimaan seseorang terhadap suatu minuman disebabkan karena cita rasa ini akan mempengaruhi permintaan suplemen herbal. Karakteristik rasa terbagi menjadi empat rasa yaitu manis, asin, pahit dan asam. Berdasarkan hasil uji organoleptik pada Tabel 3 untuk parameter rasa menunjukkan bahwa tingkat kesukaan panelis terhadap rasa suplemen herbal, nilai rata-rata skornya 4,6 6 (suka - sangat suka), terdapat pada perlakuan teknik perlakuan rajangan dan perlakuan sari dari setiap taraf konsentrasi. sedangkan pada teknik perlakuan puree dan perlakuan sari termal, diperoleh tingkat kesukaan panelis rata-rata 3,7 - 4,1 (agak tidak suka - agak suka). Rasa yang paling disukai oleh panelis adalah pada teknik kombinasi metode perajangan dan perlakuan sari pada taraf konsentrasi yang rendah yaitu $\mathrm{k}_{1}$ (bawang putih $150 \mathrm{~g}$ dan jahe $150 \mathrm{~g}$, lemon $300 \mathrm{~g}$ ). Kombinasi perajangan dengan sari lebih disukai panelis karena perajangan/ketebalan irisan yang digunakan tidak terlalu tipis yaitu berdiameter $2,5 \mathrm{~cm}$. Menurut Siswanto (2004), irisan yang tidak terlalu tipis akan mempertahankan senyawa aktif dari bahan sehingga ke khasan bahan masih terjaga. Perlakuan sari menggunakan teknik penyaringan yang memisahkan padatan dengan cairan setelah proses pemasakan bahan. Dari hal tersebut dapat disimpulkan bahwa kombinasi perlakuan perajangan dan perlakuan sari dapat menjaga ke khasan rasa dari senyawa aktif bahan dan memisahkan padatan dengan cairan sehingga suplemen yang dihasilkan tidak menyisakan ampas.

\section{Aroma}

Aroma merupakan suatu karakteristik nilai dalam produk yang secara langsung dapat diindera oleh panelis. Kepekaan indera pembauan biasanya lebih tinggi dari indera pencicipan. Berdasarkan Tabel 3 pada parameter aroma suplemen herbal menunjukkan bahwa rata-rata tingkat kesukaan panelis sangat rendah yaitu 2,3 3,5 (tidak suka - agak tidak suka). sedangkan parameter yang (agak suka suka) terdapat pada perlakuan rajangan. semakin tinggi taraf konsentrasi bawang putih pada suplemen herbal maka semakin rendah tingkat kesukaan aroma oleh panelis. Hal ini dikarenakan dari segi teknik perajangan atau arah dari pengirisan yang secara melintang dan ketebalan irisan. Ketebalan irisan yang digunakan pada penelitian ini yaitu berdiameter $2,5 \mathrm{~cm}$ dan irisan arah melintang untuk semua bahan. Ketebalan yang digunakan tersebut sudah 
Versi Online:

http://www.profood.unram.ac.id/index.php/profood e-ISSN: 2443-3446

cukup untuk menimalisir senyawa aktif yang mudah menguap pada bahan yang digunakan. Menurut Siswanto (2004), perajangan merupakan proses pengubahan bentuk produk tanaman obat menjadi bentuk lain seperti irisan. Irisan yang terlalu tipis tidak baik karena senyawa aktif yang terkandung akan mudah menguap dan arah irisan yang melintang dianjurkan digunakan agar sel-sel yang mengandung minyak atsiri yang menimbulkan aroma khas dari bahan tidak pecah dan kadarnya tidak menurun akibat penguapan.

\section{Warna}

Warna merupakan atribut yang dapat menarik konsumen pada suatu produk melalui penglihatan. Warna merupakan faktor yang harus dipertimbangkan dalam pengembangan produk, karena panelis akan menilai suatu produk pangan yang baru pertama pada penampakan secara visual. Warna merupakan salah satu bentuk visual yang dipertimbangkan oleh konsumen (Winarno, 2004).

Hasil pengujian sensori dengan metode hedonik menunjukkan bahwa ratarata skor 5-5,6 (suka-sangat suka) pada perlakuan rajangan, sari dan perlakuan sari termal. sedangkan tingkat kesukaan panelis yang paling rendah terdapat pada perlakuan puree dari berbagai taraf konsentrasi. Hal ini
Pro Food (Jurnal Ilmu dan Teknologi Pangan)

Vol 6 No. 1 Mei 2020

ISSN: 2443-1095

di sebabkan karena pada perlakuan puree, kombinasi bahan menghasilkan produk suplemen herbal dengan warna kurang cerah dibandingkan dengan perlakuan rajangan, perlakuan sari serta perlakuan sari termal. Diduga hal ini karena terjadi pembentukan turunan-turunan pigmen yang berwarna gelap. Menurut Pomeranz et al. (1978) dalam Oktaviani (1987), dengan terbentuknya turunan pigmen yang berwarna gelap, perbandingan sinar yang direfleksikan dengan sinar yang diserap menjadi lebih kecil sehingga nilai kecerahan juga semakin rendah.

Gambar 3, menunjukkan evaluasi sensori yang dilakukan pada suplemen herbal dengan menggunakan panelis 15 orang. Hasil dari evaluasi sensori didapatkan dalam bentuk sarang laba-laba dari setiap teknik kombinasi dan konsentrasi pada suplemen herbal.

\section{Penerimaan Keseluruhan}

Atribut penerimaan keseluruhan merupakan parameter yang penting dalam penerimaan produk suplemen herbal. Gambar 3 menunjukkan keragaman tingkat kesukaan panelis terhadap suplemen herbal. Rata-rata tingkat kesukaan secara keseluruhan terdapat pada teknik perlakuan rajangan dan perlakuan sari.

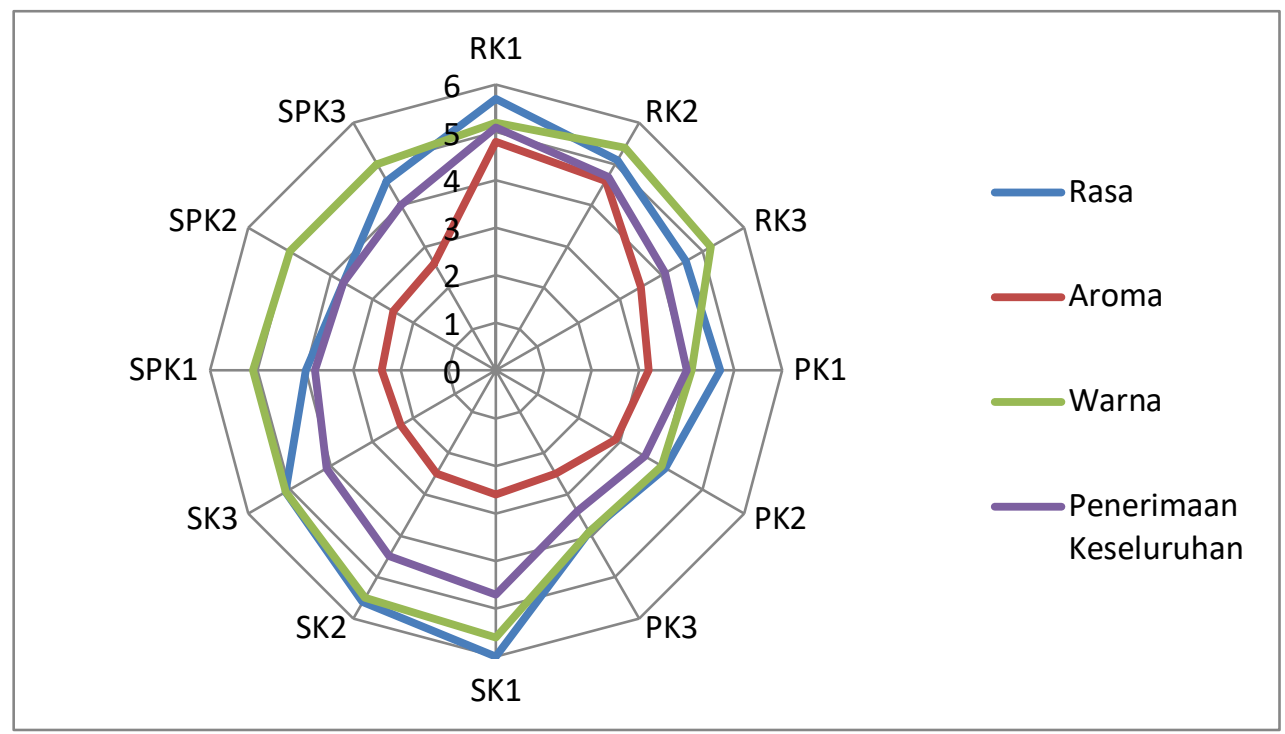

Gambar 3. Hasil Analisis Uji Hedonik Pada Suplemen Herbal 
Versi Online:

http://www.profood.unram.ac.id/index.php/profood e-ISSN: 2443-3446

\section{KESIMPULAN}

Penelitian ini dapat disimpulkan bahwa nilai antioksidan yang sangat kuat $\left(\mathrm{IC}_{50}<50\right)$ terdapat pada teknik kombinasi bahan dengan perlakuan perajangan dan konsentrasi paling rendah ( $K_{1}$ bawang putih $150 \mathrm{~g}$ dan jahe $150 \mathrm{~g}$, lemon $300 \mathrm{~g}$ ) sedangkan pada teknik kombinasi dan konsentrasi campuran bahan lainnya pada sampel suplemen herbal memiliki nilai antioksidan kuat (IC 5050 -100). Suplemen herbal dari campuran bawang putih, jahe, lemon dan madu mampu menjadi salah satu alternatif produk sebagai asupan antioksidan alami bagi tubuh.

\section{DAFTAR PUSTAKA}

Ahmad, R., Munim, A. dan Elya, B. 2012. Study of Antioxidant Activity With Reduction of Free Radical DPPH and Xanthine Oxidase Inhibitor of the Extract Ruellia tuberosa Linn Leaf. International Research Journal of Pharmacy 3(11).

Chao, Z. L. 2014. Structure-Activity Relationships of Antioxidant Activity in Vitro about Flavonoids Isolated from Pyrethrum Tatsienense. JICEP 3 (3) :123 - 127.

Dewi, T., Alifah I., Bhayangkara T., P. dan Jason G. J. 2016. Pengujian Aktivitas Antioksidan Menggunakan Metode DPPH pada Daun Tanjung (Mimusops elengi $\mathrm{L})$. Prosiding Seminar Nasional Teknik Kimia 1-7.

Jothy, S.L., Zuraini, Z. dan Sasidharan, S. 2011. Phytochemicals Screening, DPPH Free Radical Scavenging and Xanthine Oxidase Inhibitory Activities of Cassia Fistula Seeds Extract. Journal of Medicinal Plants Research 5 (10) : 1941 - 1947.

Kraujalytė, K., Leitner, E. dan Venskutonis, R.P. 2012. Chemical and Sensor Characterisation of Aroma of Vibornum opulus Fruits by Solid Phase Microextraction-Gas Chromatography-Olfactometry. Journal Food Chemistry 132:717723.
Pro Food (Jurnal Ilmu dan Teknologi Pangan)

Vol 6 No. 1 Mei 2020

ISSN: 2443-1095

Mantiri, N.C., Awaloei, H. dan Posangi, J. 2013. Perbandingan Efek Analgetik Perasan Rimpang Jahe merah (Zingiber officinale var. rubrum Thelaide) Dengan Aspirin Dosis Terapi pada Mencit (Mus musculus). Jurnal e-Biomedik (eBM) 1 (1) : 518523.

Mateen, S., Moin, S., Khan, A.Q., Zafar, A. dan Fatima, N., 2016. Peningkatan Pembentukan Spesies Oksigen Reaktif dan Stres Oksidatif pada Rheumatoid Arthritis. PloS satu 11 (4).

Molyneux, P. 2004. The Use of the Stable Free Radical Diphenylpicryl-Hydrazyl (DPPH) for Estimating Antioxidantactivity. Songklanakarin Journal of Science Technology 26(2) : $211-216$.

Muchtadi, D. 2013. Antioksidan dan Kiat Sehat di Usia Produktif. Alfabeta. Bandung.

Nizhar, U. 2012. Level Optimum Sari Buah Lemon (Citrus Limon) Sebagai Bahan Penggumpal Pembuatan Keju Cottage. Skripsi. Fakultas Peternakan, Universitas Hasanuddin. Makassar.

Oktaviani, L. 1987. Perubahan-Perubahan yang Terjadi pada Ekstrak Warna Hijau Daun Suji (Pleomele angustifolia) Selama Penyimpanan. Skripsi. Fakultas Teknologi Pertanian, Institut Pertanian Bogor. Bogor.

Prasonto, D., Riyanti, E. dan Gartika, M. 2017. Uji Aktivitas Antioksidan Ekstrak Bawang Putih (Allium sativum). ODONTO Dental Journal 4 (2) : 122-128.

Siswanto, Y. W. 2004. Penanganan Hasil Panen Tanaman Obat Komersial. Penebar Swadaya. Jakarta.

Suhaling, S,. 2010. Uji Aktivitas Antioksidan Ekstrak Metanol Kacang Merah (Phaseolus vulgaris L.) Dengan Metode DPPH. Skripsi. Universitas Islam Alauddin. Makasar.

Sunarni, T. 2007. Aktivitas Antioksidan Penangkap Radikal Bebas Beberapa kecambah Dari Biji Tanaman Familia 
Versi Online:

http://www.profood.unram.ac.id/index.php/profood e-ISSN: 2443-3446

Papilionaceae. Jurnal Farmasi Indonesia 2 (2) : 53-61.

Supriyanti, H. 2015. Untung Besar Budidaya Jahe Merah. Araska. Yogyakarta.

Winarno, F.G. 2004. Kimia Pangan dan Gizi. Gramedia Pustaka Utama. Jakarta.

Winarsi, H. 2007. Antioksidan Alami dan Radikal Bebas. Penerbit Kanisius. Yogyakarta.

Yuhernita, Juniarti. 2011. Analisis Senyawa Metabolit Sekunder dari Ekstrak Metanol Daun Surian yang berpotensi Sebagai Antioksidan. Makara Sains 15 (1) : 48 - 52.

Badan Standarisasi Nasional. 2006. SNI 01-

\section{6-2006. Petunjuk Pengujian Organoleptik dan atau Sensori. Badan Standarisasi Nasional. Jakarta.}

